\title{
Clinical course and predictors of death in prosthetic valve endocarditis over a 20-year period
}

\author{
Hector Alonso-Valle, MD, PhD, ${ }^{a}$ Concepcion Fariñas-Álvarez, MD, PhD, ${ }^{\mathrm{b}}$ Jose Daniel García-Palomo, MD, \\ $\mathrm{PhD},{ }^{\mathrm{c}}$ Jose Manuel Bernal, MD, PhD ${ }^{\mathrm{d}}$ Rafael Martín-Durán, MD, PhD, Jose Francisco Gutiérrez Díez, MD, \\ $\mathrm{PhD},{ }^{\mathrm{d}}$ Jose Manuel Revuelta, MD, PhD, ${ }^{\mathrm{d}}$ and M. Carmen Fariñas, MD, $\mathrm{PhD}^{\mathrm{c}}$
}

Objective: To compare early and late outcome of patients with prosthetic valve endocarditis treated medically versus surgically and to determine predictors of in-hospital death. We retrospectively reviewed patient's clinical records, including laboratory findings, surgery, and pathologic files, in an acute-care, 1200-bed teaching hospital.

Methods: One hundred thirty-three episodes of definite prosthetic valve endocarditis as defined by the Duke University diagnostic criteria occurred in 122 patients from January 1986 to December 2005. Logistic regression model was used to identify prognostic factors of in-hospital mortality. Long-term follow-up was made to assess late prognosis.

Results: Bioprostheses were involved in $52 \%$ of cases and mechanical valves in $48 \%$. The aortic valve was affected in $45 \%$ of patients. Staphylococcus epidermidis was isolated in $23 \%$ of cases, Streptococcus spp in $21 \%, S$ aureus in $13 \%$, and Enterococcus in $8 \%$. Cultures were negative in $18 \%$ of cases. Twenty-six patients were treated medically and 107 with combined antibiotics and valve replacement. The operative mortality was $6.5 \%$ and the in-hospital mortality, $29 \%$. Presence of an abscess at echocardiography, urgent surgical treatment, heart failure, thrombocytopenia, and renal failure were significant predictors of in-hospital death. Kaplan-Meier survival at 12 months was $42 \%$ in patients treated medically and $71 \%$ in those treated surgically $(P=.0007)$. Freedom from endocarditis was $91 \%$ at the end of follow-up.

Conclusions: Prosthetic valve endocarditis is a serious condition with high mortality. Patients with perivalvular abscess had a worse prognosis, and combined surgical and medical treatment could be the preferred approach to improve outcome. (J Thorac Cardiovasc Surg 2010;139:887-93)

Prosthetic valve endocarditis (PVE) is a rare but severe complication of valve replacement and has been reported to occur with an incidence of 0.98 per 100 patient-years. ${ }^{1}$ The cumulative incidence at 5 years is $3 \%$ and at 10 years is $5 \%,{ }^{2}$ with a case-mortality rate ranging from $25 \%$ to $59 \%,{ }^{3}$ despite improvements in prophylaxis, diagnosis, and treatment. The best therapeutic option in PVE is still debated. Although surgical therapy is said to represent the best choice, ${ }^{4,5}$ medical therapy can be sufficient in some patients. ${ }^{6}$

\footnotetext{
From the Emergency Department, ${ }^{\text {a }}$ Hospital Universitario Marqués de Valdecilla, Universidad de Cantabria, Santander, Spain; Division of Preventive Medicine, ${ }^{\mathrm{b}}$ Hospital Sierrallana, Torrelavega, Cantabria, Spain; Infectious Diseases Unit, ${ }^{\mathrm{c}}$ Hospital Universitario Marqués de Valdecilla, Universidad de Cantabria, Santander, Spain; Department of Cardiovascular Surgery, ${ }^{\mathrm{d}}$ Hospital Universitario Marqués de Valdecilla, Universidad de Cantabria, Santander, Spain; and Service of Cardiology, ${ }^{\mathrm{e}}$ Hospital Universitario Marqués de Valdecilla, Universidad de Cantabria, Santander, Spain.

Disclosures: None.

Received for publication Feb 17, 2009; revisions received April 22, 2009; accepted for publication May 22, 2009; available ahead of print July 13, 2009.

Address for reprints: M. Carmen Fariñas, MD, PhD, Infectious Diseases Unit, Department of Internal Medicine, Hospital Universitario Marqués de Valdecilla, Avda Valdecilla s/n, E-39008 Santander, Spain. (E-mail: farinasc@unican.es). $0022-5223 / \$ 36.00$

Copyright (C) 2010 by The American Association for Thoracic Surgery doi:10.1016/j.jtcvs.2009.05.042
}

The objective of this study was to describe the clinical features of patients with PVE, to determine predictors of in-hospital death, and to compare early and late outcome of patients with PVE treated medically versus surgically.

\section{PATIENTS AND METHODS}

The study was conducted at an acute-care, 1200-bed teaching hospital. The hospital has a department of cardiovascular surgery, a cardiology service, and a unit of infectious diseases and has been a reference center of cardiovascular surgery for other hospitals in the country. From January 1986 to December 2005, a total of 133 consecutive episodes of definite PVE as defined by Duke University diagnostic criteria ${ }^{7}$ were treated at our institution. A retrospective review of the patient's clinical records, including laboratory findings, surgery, and pathologic files, forms the basis of the present report. The primary end points of the study were in-hospital death and survival at 12 months after combined medical and surgical treatment versus medical therapy alone. The study was approved by the Institutional Review Board.

Early PVE was defined as the diagnosis of PVE within 60 days of prosthetic valve implantation, and late-onset was defined as PVE occurring 2 or more months after valve replacement. ${ }^{8}$ All patients were scheduled for 4- to 8-week antibiotic therapy. All operations were performed at the department of cardiovascular surgery of our hospital. Urgent surgery was defined as valvular replacement performed within 24 hours after hospital admission. Indications of surgery and the choice of the best valvular substitute were left to the discretion of the attending physician. Intraoperative decisions and the treatment protocols for these patients varied over the study period. Briefly, if the indication of surgical treatment was an urgent operation $(<24$ hours after admission), the infected prosthesis was substituted by a new one according 


\author{
Abbreviations and Acronyms \\ $\mathrm{CI}=$ confidence interval \\ NYHA $=$ New York Heart Association \\ PVE $=$ prosthetic valve endocarditis \\ $\mathrm{RR} \quad=$ risk ratio
}

\section{Statistical Analysis}

A logistic regression model was used to evaluate the effect of explanatory variables on in-hospital mortality. In both the univariate and multivariable analysis, continuous variables were categorized using the most clinically relevant cutoff points. Variables were entered into a stepwise backward multiple logistic regression model. Results are expressed as crude and adjusted odds ratios with $95 \%$ confidence intervals (CIs). All factors were adjusted by sex, age, year of diagnosis of PVE, referral hospital, and nosocomial infection after original valve replacement. Survival analysis was used to compare event rates during the follow-up period with comparisons made with the Kaplan-Meier method. Mortality rates for PVE were evaluated by plotting the survival distribution derived from Kaplan-Meier estimates, and differences in survival were assessed by the log-rank test. A Cox regression analysis was performed to assess the effect of the different variables on the risk of death. The risk ratio (RR) and the $95 \%$ CI were calculated. Data were analyzed using Stata statistical software (Release 8.0, Stata Corporation, College Station, Tex) and SPSS (version 11.5; SPSS Inc, Chicago, Ill).

\section{RESULTS}

A total of 133 episodes of PVE were diagnosed (112 patients had 1 episode, 9 patients had 2 episodes, and 1 patient had 3 episodes). There were 87 men and 34 women with a mean age of 59 years (95\% CI: 56-62). During the same period, 6079 valve replacement operations were performed, with an incidence of PVE of $2.2 \%$. Sixty-nine episodes occurred in patients who had bioprosthetic valve replacement and the remaining 64 in patients who had mechanical valve replacement. Location of infected prosthesis included aortic in 60 cases, mitral in 37, and mitroaortic in 36. Laboratory findings showed leukocytosis or leukopenia in $60 \%$ of the episodes, sedimentation rate $>40 \mathrm{~mm} / \mathrm{h}$ in $24 \%$, and serum hemoglobin $<10 \mathrm{~g} / \mathrm{dL}$ in $8 \%$. Echocardiography revealed vegetations in $63.1 \%$ of cases, prosthetic valve dysfunction in $71.4 \%$, abscess in $39.3 \%$, and aortoventricular dehiscence in $9.7 \%$.

Of the 133 cases of PVE, there were 24 cases $(18 \%)$ of early onset PVE and $109(82 \%)$ of late-onset PVE. Mechanical PVE was more frequent in the early onset PVE group ( $78 \%$ vs $22 \%$ ), whereas bioprosthetic PVE was more frequent in the late-onset group ( $58 \%$ vs $42 \%$ ). Coagulasenegative staphylococci were observed most often in both early PVE (47\%) and late PVE (29\%) groups. Staphylococcus aureus was the second most frequent organism in early PVE (25\%) and Streptococcus viridans in late PVE (19\%). The percentage of methicillin-resistant $S$ aureus was higher in early PVE $(40 \%, 10 / 25)$ than in late PVE $(23 \%, 3 / 13)$. Cultures were negative in 24 cases (18\%). Complications during hospitalization occurred in 96 of the 133 episodes of PVE $(72.2 \%)$, with a rate of $66.7 \%(16 / 24)$ in early PVE and 73.4\% (80/109) in late PVE. Clinical features, microbiologic data, and complications in all episodes of PVE as well as in the groups of early and late PVE are shown in Table 1.

Thirty-nine patients died, for an in-hospital mortality rate of $29.3 \%$. Causes of death included heart failure or 
TABLE 1. Clinical characteristics, microbiologic data, and complications in 133 episodes of PVE

\begin{tabular}{|c|c|c|c|}
\hline & All episodes & Early PVE & Late PVE \\
\hline No. cases & 133 & 24 & 109 \\
\hline \multicolumn{4}{|l|}{ Clinical features } \\
\hline Fever & $106(79.7)$ & $17(70.8)$ & $89(84.0)$ \\
\hline Heart failure & $87(65.4)$ & $18(75)$ & $69(63.3)$ \\
\hline Systemic embolism & $6(4.5)$ & $1(4.2)$ & $5(4.6)$ \\
\hline Splenomegaly & 15 (11.3) & $1(4.2)$ & $14(12.8)$ \\
\hline $\begin{array}{l}\text { Osler nodes, } \\
\text { Janeway lesions }\end{array}$ & $7(4.3)$ & $1(4.2)$ & $4(3.7)$ \\
\hline $\begin{array}{l}\text { New or changing } \\
\text { murmur }\end{array}$ & $85(63.9)$ & $13(54.2)$ & $72(66.1)$ \\
\hline $\begin{array}{l}\text { Causative } \\
\text { microorganisms }\end{array}$ & $109(81.9)$ & $21(87.5)$ & $88(80.7)$ \\
\hline $\begin{array}{l}\text { Coagulase-negative } \\
\text { Staphylococci }\end{array}$ & $36(27.1)$ & $9(37.5)$ & $27(24.8)$ \\
\hline $\begin{array}{l}\text { Staphylococcus } \\
\text { aureus }\end{array}$ & $17(12.8)$ & $5(20.8)$ & $12(11.0)$ \\
\hline $\begin{array}{l}\text { Methicillin- } \\
\quad \text { sensitive } S \text { aureus }\end{array}$ & $12(9.0)$ & $3(12.5)$ & $9(8.2)$ \\
\hline $\begin{array}{l}\text { Methicillin-resistant } \\
\quad \text { S aureus }\end{array}$ & $5(3.7)$ & $2(8.3)$ & $3(2.7)$ \\
\hline $\begin{array}{l}\text { Streptococcus } \\
\text { viridans }\end{array}$ & $21(15.8)$ & $1(4.2)$ & $20(15.1)$ \\
\hline Enterococcus & $9(6.8)$ & $1(4.2)$ & $8(7.3)$ \\
\hline Diphtheroids & $1(0.7)$ & $1(4.2)$ & 0 \\
\hline $\begin{array}{l}\text { Gram-negative } \\
\text { bacilli }\end{array}$ & $4(3.0)$ & 0 & $4(3.7)$ \\
\hline Peptococcus spp & $1(0.7)$ & 0 & $1(0.9)$ \\
\hline Candida spp & $4(3.0)$ & 0 & $4(3.7)$ \\
\hline Miscellaneous & $16(12.0)$ & $4(16.7)$ & $12(11.0)$ \\
\hline Negative culture & $24(18.0)$ & $3(12.5)$ & $21(19.3)$ \\
\hline $\begin{array}{c}\text { Complications during } \\
\text { hospitalization }\end{array}$ & $96(72.2)$ & $16(66.7)$ & $80(73.4)$ \\
\hline Respiratory failure & $23(17.3)$ & $5(20.8)$ & $18(16.5)$ \\
\hline Severe heart failure & $42(31.6)$ & $7(29.2)$ & $35(32.1)$ \\
\hline Renal failure & $47(35.3)$ & $9(37.5)$ & 38 (34.9) \\
\hline $\begin{array}{l}\text { Third-degree } \\
\text { atrioventricular block }\end{array}$ & $13(9.8)$ & $2(8.3)$ & $11(10.1)$ \\
\hline Neurologic events & $18(13.5)$ & $3(12.5)$ & $15(13.8)$ \\
\hline Uncontrolled infection & $19(14.3)$ & $4(16.7)$ & $15(13.8)$ \\
\hline Septic shock & $13(9.8)$ & $4(16.7)$ & $9(8.2)$ \\
\hline
\end{tabular}

cardiogenic shock in 13 patients, multiorgan failure in 9 , uncontrolled infection in 8, and other in 9. A total of 107 patients had surgical valve replacement during the acute phase of the disease. Urgent surgery was necessary in 51 cases $(38.3 \%)$.

In the univariate analysis (Table 2), factors significantly associated with in-hospital death were onset of PVE within the first 3 months after the index valve replacement operation, leukopenia or leukocytosis, presence of an abscess detected by echocardiography or at surgery, left ventricular ejection fraction $<30 \%$, urgent surgery, respiratory failure,
TABLE 2. Results of univariate analyses: Risk factors for in-hospital death in 133 episodes of PVE

\begin{tabular}{|c|c|c|c|}
\hline & \multicolumn{3}{|c|}{ Crude mortality } \\
\hline & $\mathbf{R R}$ & $95 \% \mathrm{CI}$ & $P$ value \\
\hline Age $>75 y$ & 1.6 & $0.6-4.3$ & NS \\
\hline $\begin{array}{l}\text { Year of PVE diagnosis 1986- } \\
\quad 1995\end{array}$ & 0.9 & $0.4-1.9$ & NS \\
\hline Female gender & 1.2 & $0.6-2.7$ & NS \\
\hline $\begin{array}{l}\text { Previous infective } \\
\text { endocarditis }\end{array}$ & 1.7 & $0.7-4.4$ & NS \\
\hline Previous valve replacement & 0.9 & $0.4-2.1$ & NS \\
\hline Comorbidity & 2.4 & $0.1-40.1$ & NS \\
\hline $\begin{array}{l}\text { Mechanical prosthesis } \\
\text { implantation }\end{array}$ & 1.1 & $0.5-2.4$ & NS \\
\hline $\begin{array}{l}\text { Involvement of the aortic } \\
\text { valve }\end{array}$ & 1.7 & $0.7-3.64$ & NS \\
\hline Early PVE & 1.9 & $0.8-4.92$ & NS \\
\hline $\begin{array}{l}\text { Onset }<3 \text { mo of index } \\
\text { operation }\end{array}$ & 2.3 & $1.1-5.4$ & .044 \\
\hline Fever & 2.0 & $0.7-5.9$ & NS \\
\hline New or changing murmur & 1.2 & $0.5-2.6$ & NS \\
\hline Systemic emboli & 2.3 & $0.4-12.1$ & NS \\
\hline $\begin{array}{c}\text { White blood cell count }<3 \times \\
10^{9} / \mathrm{L} \text { or }>16 \times 10^{9} / \mathrm{L}\end{array}$ & 2.8 & $1.1-6.9$ & .023 \\
\hline Positive blood cultures & 1.0 & $0.3-2.7$ & NS \\
\hline $\begin{array}{l}\text { Staphylococcus aureus } \\
\text { infection }\end{array}$ & 2.1 & $0.7-2.0$ & NS \\
\hline $\begin{array}{l}\text { Vegetation in the } \\
\text { echocardiogram }\end{array}$ & 1.5 & $0.6-3.2$ & NS \\
\hline $\begin{array}{l}\text { Abscess in the } \\
\text { echocardiogram }\end{array}$ & 3.5 & $1.6-7.8$ & .0016 \\
\hline Prosthesis regurgitation & 0.9 & $0.4-1.9$ & NS \\
\hline New valve dehiscence & 2.2 & $0.7-7.2$ & NS \\
\hline $\begin{array}{l}\text { Left ventricular ejection } \\
\text { fraction }<30 \%\end{array}$ & 17.0 & $1.4-210$ & .0082 \\
\hline Surgical treatment & 0.5 & $0.2-1.2$ & NS \\
\hline Urgent surgery & 3.9 & $1.5-9.8$ & .0035 \\
\hline Abscess detected at surgery & 2.7 & $1.1-6.5$ & .024 \\
\hline Respiratory failure & 4.2 & $1.6-10.7$ & .0017 \\
\hline Renal failure & 2.2 & $1.03-4.8$ & .038 \\
\hline Heart failure & 9.7 & $4.1-22.9$ & .00001 \\
\hline Thrombocytopenia & 4.5 & $1.0-19.6$ & .034 \\
\hline $\begin{array}{l}\text { Third-degree atrioventricular } \\
\text { block }\end{array}$ & 1.6 & $0.5-5.1$ & NS \\
\hline Neurologic events & 2.2 & $0.8-5.9$ & NS \\
\hline Complicated PVE & 1.7 & $0.7-4.2$ & NS \\
\hline Uncontrolled infection & 14 & $4.3-46.2$ & .00001 \\
\hline Severe sepsis & 10 & $1.9-50.9$ & .0009 \\
\hline Septic shock & 41 & $5.1-332.3$ & .00001 \\
\hline
\end{tabular}

$P V E$, Prosthetic valve endocarditis; $R R$, risk ratio; $C I$, confidence interval.

renal failure, heart failure, thrombocytopenia, uncontrolled infection, severe sepsis, and septic shock. All these factors except thrombocytopenia were significant predictors of inhospital mortality in the multivariate analysis (Table 3). In addition, the presence of third-degree atrioventricular block 
TABLE 3. Results of multivariate analyses: Risk factors for in-hospital death in 133 episodes of PVE

\begin{tabular}{|c|c|c|c|}
\hline & \multicolumn{2}{|c|}{ Adjusted mortality } & \multirow[b]{2}{*}{$P$ value } \\
\hline & OR* & $95 \% \mathrm{CI}$ & \\
\hline $\begin{array}{l}\text { Onset }<3 \text { mo of index } \\
\text { operation }\end{array}$ & 7.0 & $1.02-47$ & .047 \\
\hline $\begin{array}{c}\text { White blood cell count }<3 \times \\
10^{9} / \mathrm{L} \text { or }>16 \times 10^{9} / \mathrm{L}\end{array}$ & 4.8 & $1.5-15.4$ & .009 \\
\hline $\begin{array}{l}\text { Abscess in the } \\
\text { echocardiogram }\end{array}$ & 3.2 & $1.3-7.8$ & .01 \\
\hline Urgent surgery & 3.9 & $1.5-9.9$ & .02 \\
\hline $\begin{array}{l}\text { Abscess detected } \\
\text { at surgery }\end{array}$ & 3.9 & $1.2-9.4$ & .019 \\
\hline Respiratory failure & 4.5 & $1.5-13.2$ & .006 \\
\hline Renal failure & 2.9 & $1.2-7.1$ & .018 \\
\hline Heart failure & 11 & $4.3-39.8$ & .0001 \\
\hline $\begin{array}{l}\text { Third-degree } \\
\text { atrioventricular block }\end{array}$ & 3.7 & $1.15-12$ & .028 \\
\hline Complicated PVE & 2.6 & $0.8-7.8$ & .085 \\
\hline Uncontrolled infection & 17 & $4.4-65.7$ & .0001 \\
\hline Severe sepsis & 11 & $1.8-61.3$ & .008 \\
\hline Septic shock & 42 & $4.9-356.8$ & .001 \\
\hline
\end{tabular}

$P V E$, Prosthetic valve endocarditis; $O R$, odds ratio; $C I$, confidence interval. *All factors adjusted by: sex, age, year of PVE onset, referral hospital, nosocomial infection after original valve replacement.

during hospitalization and complicated PVE were also significant predictors in the logistic regression model.

In 26 episodes of PVE occurring in 25 patients, medical treatment only was indicated. One patient with 2 episodes of PVE received only medical treatment because prosthetic valve dysfunction was not observed. In the remaining 24 patients, surgical treatment was not performed for the following reasons: absence of prosthetic valve dysfunction in 10 , severe sepsis in 5, cerebral embolism in 3, cardiogenic shock in 2, acute renal failure in 1, and unknown cause in 3. As shown in Table 4, demographic and clinical features of surgically treated and nonsurgically treated patients were similar, although medically treated patients were significantly younger and a significantly lower percentage of patients had complicated PVE as compared with the surgical group. Moreover, more patients in the surgical group were in NYHA functional class IV. The in-hospital mortality rate was $26 \%$ in the medical-surgical group versus $42 \%$ in the medical therapy alone group $(P=\mathrm{NS})$.

Recurrent PVE was observed in only 12 cases $(9 \%)$ : a recurrent episode of valve infection was detected in 10 episodes and a relapse in 2 . Fifty percent of patients were carriers of mechanical valve prosthesis, and $50 \%$ of biologic prosthesis (patients with multiple valve replacement in $60 \%$ of cases). Only 1 case had a positive culture in which Candida albicans was recovered.

The mean length of follow-up was 32.2 months (standard deviation 46.8, range 0-212 months). Freedom from endocarditis was $91 \%$ at the end of follow-up. Cumulative sur-
TABLE 4. Demographic and clinical features between the surgically treated and nonsurgically treated groups of PVE

\begin{tabular}{|c|c|c|c|}
\hline & $\begin{array}{c}\text { Surgical, n }(\%) \\
\quad(\mathbf{n}=107)\end{array}$ & $\begin{array}{c}\text { Medical therapy } \\
\text { only, } \mathbf{n}(\%) \\
(\mathbf{n}=\mathbf{2 6}) \\
\end{array}$ & $P$ value \\
\hline Age, years, mean (SD) & $57(15)$ & $66(14)$ & .01 \\
\hline Male patients & $75(70.1)$ & $15(57.7)$ & .25 \\
\hline Diabetes mellitus & $6(5.6)$ & $4(15.4)$ & .11 \\
\hline Renal failure & $1(0.9)$ & $1(3.8)$ & .35 \\
\hline Neoplasms & $3(2.8)$ & $2(7.7)$ & .25 \\
\hline Intravenous drug users & $2(1.9)$ & 0 & .65 \\
\hline Immunosuppression & $3(2.8)$ & 0 & .52 \\
\hline Severe comorbidity & $2(1.9)$ & 0 & .65 \\
\hline Early PVE & $17(15.9)$ & $7(26.9)$ & .25 \\
\hline Fever & $82(76.6)$ & $24(92.3)$ & .10 \\
\hline $\begin{array}{l}\text { NYHA functional } \\
\text { class IV }\end{array}$ & $40(37.4)$ & $4(15.4)$ & .36 \\
\hline $\begin{array}{l}\text { Staphylococcus aureus } \\
\text { infection }\end{array}$ & $14(13.1)$ & $4(15.4)$ & .75 \\
\hline Complicated PVE & $83(77.6)$ & $13(50)$ & .007 \\
\hline Severe sepsis & $4(3.7)$ & $5(19.2)$ & .14 \\
\hline
\end{tabular}

vival was $68 \%$ at 3 months, $64 \%$ at 6 months, and $63 \%$ at 12 months. Among the 94 patients who were discharged alive from the hospital, $26(27 \%)$ died during a mean follow-up period of 31 months. As shown in Figure 1, 12 month survival was $71 \%$ in the medical-surgical group compared with $42 \%$ in the medical group (log-rank test 11.48 , $P=.0007)$. In the Cox regression analysis, surgical treatment was a significant predictor of survival $(\mathrm{RR}=0.43$, $95 \%$ CI $0.24-0.75, P=0.003)$. Differences in survival regarding early and late PVE and study period (19861995 vs 1996-2005) were not observed.

\section{DISCUSSION}

Infection of intracardiac prostheses is a serious, often lifethreatening complication of valve replacement surgery ${ }^{14}$ despite prompt diagnosis, antibiotic therapy, and the frequent indication of replacement of the infected valve. The present study carried out in a large population of patients with PVE also documents the high morbidity and mortality of this condition.

One major problem when assessing the prognosis of PVE is that previous studies have included a spectrum of heterogeneous patients in whom the diagnosis of PVE was not proven. In the study of Kuyvenhoven and colleagues, ${ }^{3}$ proven PVE was only documented in 39 of 70 episodes, whereas in the study of $\mathrm{Yu}$ and associates, ${ }^{15}$ definite endocarditis was diagnosed in 42 of 74 patients. To allow valid interpretation of the data in our study, we included only patients with definite diagnosis of PVE according to Duke criteria. ${ }^{7}$ In our population of patients with definite PVE 


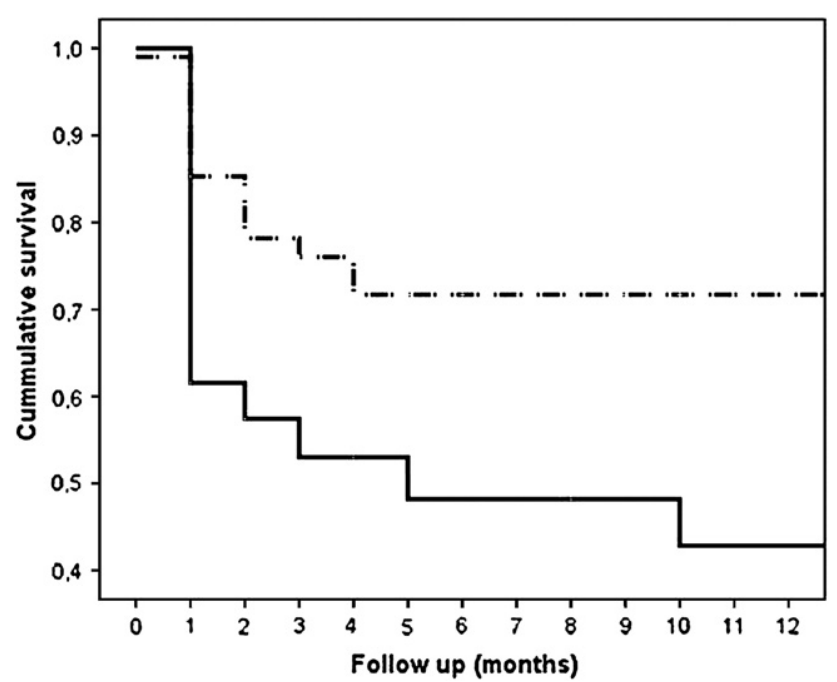

FIGURE 1. Long-term survival of patients with prosthetic valve endocarditis after combined medical and surgical treatment (upper line) or medical treatment alone (lower line).

endocarditis in which patients with only bacteremia and no other major criteria of endocarditis were excluded, $18 \%$ of cases of PVE occurred within the first 60 days after valve replacement. This percentage is slightly lower than that reported in previous studies, in which about one-third of patients had early onset PVE and two-thirds had late-onset PVE. ${ }^{16}$ Although our study showed a higher mortality in patients with early PVE (42\%) compared with those with late PVE $(26 \%)$, there were no statistically significant differences, which is in contrast with other studies. ${ }^{6,10}$

Due to the complexity of PVE, different clinical findings on admission and late complications may influence the outcome. Several studies have suggested that aortic prosthe$\operatorname{ses}^{17}$ and infection of a mechanical valve ${ }^{16}$ rather than a porcine valve are associated with a higher mortality, but other studies and our data showed no differences with regard to these variables. Leukocytosis or leukopenia on admission was the only variable significantly associated with in-hospital death. Although some studies have shown an association between abnormal white blood cell count and mortality in infective endocarditis, ${ }^{6}$ as far as we are aware, this is the first study showing that this marker is an independent predictor of mortality in the setting of PVE.

According to microbiology, early PVE is caused by contamination of the artificial valve at the time of implantation or by perioperative bacteremia, so that the most frequently encountered pathogens in early PVE are coagulase-negative staphylococci, followed by $S$ aureus and Enterococcus. ${ }^{18}$ On the other hand, late PVE can be caused by different microorganisms. ${ }^{19}$ In agreement with other studies, we found that coagulase-negative Staphylococcus was the most common causative microorganism for PVE, although recent studies showed an increase in PVE caused by $S$ aureus. ${ }^{14}$
A significant association between $S$ aureus infection and mortality in PVE has been reported. In our study, a trend toward a higher mortality with staphylococcal infection was noted, but statistical significance in the multivariate analysis was not reached.

Echocardiographic findings have an important role in the diagnosis and management of PVE. ${ }^{20}$ Echocardiographic signs include vegetations on and around the prosthetic valve, valve dysfunction (stenosis, regurgitation, perivalvular leak), and invasion of perivalvular tissue by abscesses and fistulae. Previous studies showed the association of periannular complications in endocarditis in the setting of prosthetic valve infection. ${ }^{20}$ However, the role of echocardiography in predicting outcome has been poorly assessed. In the study of Habib and associates, ${ }^{5}$ the presence of annular abscess was not associated with increased mortality. In our study, we observed a 29\% rate of echocardiographic abscess in PVE patients, which is higher than the results obtained in other studies, which ranged from $12 \%$ to $19 \%{ }^{6,12,21}$ The mortality of these patients was statistically significant in multivariate analysis. In a recent prospective multicenter study, abscess formation was included among the strongest predictors of mortality. ${ }^{12}$ We also observed a worse prognosis in patients with a low ejection fraction. There are few comparable data in the literature concerning the ejection fraction as a predictor of outcome in patients with PVE. ${ }^{22}$

The optimal treatment in PVE is still debated, but surgery has become a mainstay in complicated PVE ${ }^{14,17,23}$ The high rate of subsequent valve failure in patients treated medically is an argument in favor of surgical treatment. However, the use and timing of surgery in an individual patient with PVE is often a difficult and complex clinical decision. Calderwood and colleagues ${ }^{9}$ showed that patients not treated surgically during their initial hospital admission are at high risk of progressive prosthesis dysfunction and require careful follow-up. In contrast, early valve surgery appears to improve the prognosis of PVE. The superiority of surgical treatment compared with antibiotic treatment alone has been demonstrated in several studies, so that an aggressive medical-surgical approach is recommended. ${ }^{9,15}$ In our study population, the surgery rate was relatively high when compare with data from the literature. The main cause was that about $65 \%$ of our patients were referred from other hospitals because of associated morbidity and a complicated clinical course of PVE. When we analyzed the outcome of patients according to the treatment received, in-hospital mortality was lower in the surgical group than in the medical group $(26 \%$ vs $42 \%$ ), although the differences were not statistically significant. Survival after 12 months of treatment, however, was markedly different in favor of surgically treated patients ( $71 \%$ vs $42 \%)$. Moreover, surgical treatment was an independent significant variable associated with favorable outcome in the Cox regression analysis $(\mathrm{RR}=0.43, P=$ .003). Other studies have also assessed the benefits of 
surgical treatment, but few of them have evaluated the impact of long-term survival. ${ }^{5,6}$ In the study of Wang and associates, ${ }^{12}$ a trend toward a benefit of surgical treatment was also reported. However, further studies are needed to define more clearly the role, timing, and effect of surgery in PVE.

Chronic heart failure is the most common cause of death in patients with $\mathrm{PVE}^{5,9}$ and also the most frequent indication of surgical treatment in complicated infective endocarditis. Heart failure in PVE results predominantly as a consequence of valve destruction and secondary severe regurgitation leading to pulmonary edema. In our study, like others, ${ }^{10}$ heart failure was one of the strongest predictors of in-hospital mortality. Uncontrolled infection, severe sepsis, and septic shock were predictors of death in the multivariate analysis, reflecting the importance of sepsis in the outcome of these patients. In addition, neurologic complications were related to an adverse outcome, as previous studies have pointed out. ${ }^{12,24}$ On the other hand, and in contrast to other studies, ${ }^{9,10}$ a relationship between complicated PVE and mortality was not observed.

After hospital discharge, the highest mortality rate was observed during the first 3 months. After this period, the survival of the patients remain stable and freedom from endocarditis was $92 \%$ at the end of the follow-up period. The differences between medical and surgical treatment in long-term outcome are similar to previous studies ${ }^{5,15}$ and add evidence of the importance of combined surgical and medical treatment as the better treatment option in these patients. In fact, surgery was a significant protective factor for survival in the Cox regression analysis. In our patients, the medically treated group showed a higher in-hospital mortality rate than the surgically treated group, although differences were not significant. Although patients in the medical therapy only group were older, a significantly lower percentage was in NYHA functional class IV and had complicated bacterial endocarditis compared with the surgical group. Comorbidities in both groups were similar. Selection of surgical treatment should be considered in an early phase of the diagnosis of PVE and probably by a multidisciplinary team (cardiologists, specialists in infectious diseases, cardiovascular surgeons). The decision of operation should not be delayed as surgical mortality is related to the amount of anatomic damage, and it is well known that anatomic destruction reflects both aggressiveness of the causative pathogen and duration of the disease.

Our study has several shortcomings. First, a prospective randomized controlled trial remains the best way to evaluate the effectiveness of different strategies in the management of PVE but such a trial would take several years to recruit a sufficient number of patients from a single center or may have to involve multiple centers, leading to a nonhomogeneous group of patients and management protocols. Thus, a retrospective review is a reasonable approach for attempting to assess predictors of outcome in patients with PVE, although retrospective studies are clearly hampered by lack of randomization and therefore bias in the selection of treatment methods. However, our surgical team had no significant differences concerning intraoperative management, and there was a formal policy in our hospital during the study period. Second, our study was performed in a referral center; this may introduce a referral bias in the result obtained, which we tried to solve by introducing this variable in the multivariate analysis. Third, survivor treatment selection bias could be detected, ${ }^{25}$ although there were no significant differences according to comorbidities or clinical situation between medical or surgical patients treated, and a significant number of patients in our study underwent urgent surgery. On the other hand, only patients who fulfilled the Dukes criteria for definite endocarditis were analyzed, which is in contrast to previous studies in which such a strict criterion was not used. Thus, our study is one of the largest single-center series published in the literature, and the present results may contribute to a better knowledge of the clinical course and outcome of this important disease.

In summary, the present findings, which should be interpreted considering the retrospective nature of the study, confirm that PVE is a serious condition with a high mortality. Patients with perivalvular abscess had a worse prognosis, and combined surgical and medical treatment could be the preferred approach to improve outcome.

We thank Marta Pulido, MD, for editing the manuscript and for editorial assistance. No external industry funding was received for the study itself or for editorial assistance.

\section{References}

1. Arvay A, Lengyel M. Incidence and risk factors of prosthetic valve endocarditis. Eur J Cardiothorac Surg. 1988;2:340-6.

2. Rutledge R, Kim BJ, Applebaum RE. Actuarial analysis of the risk of prosthetic valve endocarditis in 1,598 patients with mechanical and bioprosthetic valves. Arch Surg. 1985;120:469-72.

3. Kuyvenhoven JP, van Rijk-Zwikker GL, Hermans J, et al. Prosthetic valve endocarditis: analysis of risk factors for mortality. Eur J Cardiothorac Surg. 1994;8: 420-4.

4. Fariñas MC, Pérez-Vázquez A, Fariñas-Alvarez C, et al. Risk factors of prosthetic valve endocarditis: a case-control study. Ann Thorac Surg. 2006;81:1284-90.

5. Habib G, Tribouilloy C, Thuny F, et al. Prosthetic valve endocarditis: who needs surgery? A multicentre study of 104 cases. Heart. 2005;91:954-9.

6. Akowuah EF, Davies W, Oliver S, et al. Prosthetic valve endocarditis: early and late outcome following medical or surgical treatment. Heart. 2003;89:269-72.

7. Durack DT, Lukes AS, Bright DK. New criteria for diagnosis of infective endocarditis: utilization of specific echocardiographic findings. Am J Med. 1994;96: 200-9.

8. Pérez-Vázquez A, Fariñas MC, García-Palomo JD, et al. Evaluation of the Duke criteria in 93 episodes of prosthetic valve endocarditis. Could sensitivity be improved? Arch Intern Med. 2000;160:1185-91.

9. Calderwood SB, Swinski LA, Karchmer AW, et al. Prosthetic valve endocarditis: analysis of factors affecting outcome of therapy. J Thorac Cardiovasc Surg. 1986; 92:776-83.

10. Wolff M, Witchitz S, Chastang C, et al. Prosthetic valve endocarditis in the ICU. Prognostic factors of overall survival in a series of 122 cases and consequences for treatment decision. Chest. 1995;108:688-94.

11. Bone RC, Balk RA, Cerra FB, et al. Definitions for sepsis and organ failure and guidelines for the use of innovative therapies in sepsis. The ACCP/SCCM 
Consensus Conference Committee. American College of Chest Physicians/Society of Critical Care Medicine. Chest. 1992;101:1644-55.

12. Wang A, Pappas P, Anstron KJ, et al. The use and effect of surgical therapy for prosthetic valve infective endocarditis: a propensity analysis of a multicenter, international cohort. Am Heart J. 2005;150:1086-91.

13. Daniel WG, Mugge A, Martin RP, et al. Improvement in the diagnosis of abscesses associated with endocarditis by transesophageal echocardiography. N Engl J Med. 1991;324:795-800.

14. Wang A, Athan E, Pappas PA, et al. Contemporary clinical profile and outcome of prosthetic valve endocarditis. JAMA. 2007;297:1354-61.

15. Yu VL, Fang GD, Keys TF, et al. Prosthetic valve endocarditis: superiority of surgical valve replacement versus medical therapy only. Ann Thorac Surg. 1994;58: 1073-7.

16. Turina M. Prosthetic valve endocarditis. Thorac Cardiovasc Surg. 1982;30:350-3.

17. Wallace SM, Walton BI, Kharbanda RK, et al. Mortality from infective endocarditis: clinical predictors of outcome. Heart. 2002;88:53-60.

18. Mylonakis E, Calderwood SB. Infective endocarditis in adults. $N$ Engl J Med. 2001;345:1318-30.
19. David TE. The surgical treatment of patients with prosthetic valve endocarditis Semin Thorac Cardiovasc Surg. 1995;7:47-53.

20. Lengyel M. The impact of transesophageal echocardiography on the management of prosthetic valve endocarditis: experience of 31 cases and review of the literature. J Heart Valve Dis. 1997;6:204-11.

21. Anguera I, Miro JM, Evangelista A, et al. Periannular complications in infective endocarditis involving prosthetic aortic valves. Am J Cardiol. 2006;98: 1261-8.

22. Jassal DS, Neilan TG, Pradhan AD, et al. Surgical management of infective endocarditis: early predictors of short-term morbidity and mortality. Ann Thorac Surg. 2006;82:524-9.

23. Habib G, Thuny F, Avierinos JF. Prosthetic valve endocarditis: current approach and therapeutic options. Prog Cardiovasc Dis. 2008;50:274-81.

24. Chu VH, Cabell CH, Benjamin DK Jr, et al. Early predictors of in-hospital death in infective endocarditis. Circulation. 2004;109:1745-9.

25. Tleyjeh IM, Ghomrawi HM, Steckelberg JM, et al. The impact of valve surgery on 6-month mortality in left-sided infective endocarditis. Circulation. 2007;115 1721-8. 